\title{
Implementing Multiple AR Markers in Learning Science Content with Junior High School Students in Thailand
}

\author{
https://doi.org/10.3991/ijet.v14i07.9855 \\ Jaitip Nasongkhla ${ }^{(凶)}$, Chanjaradwichai Supadaec, Thanyaporn Chiasiriphan \\ Chulalongkorn University, Bangkok, Thailand \\ jaitip.n@chula.ac.th
}

\begin{abstract}
This study demonstrates a supplementary classroom technology using an Augmented Reality (AR) application to enhance students in learning Genetics at Junior High School in Thailand. The tool provides visual cards of concepts about Genetics with multiple AR markers (cards). An interactive experience provides students a multiple-choice format to respond to different cases (questions). Using a purposive sampling technique, sixty students from the 9th grade compared and selected AR markers to generate an animated twodimensional graphic with sound feedback. In addition, the students' learning scores were compared among the groups of different analytical thinking abilities who used single and multiple AR markers. The results found the potential of using Augmented Reality (AR) in supporting students' learning especially in improving analytical thinking ability.
\end{abstract}

Keywords-Augmented reality, genetics, multiple-choice format, Thailand

\section{Introduction}

Thailand moves forwards to knowledge economy society. National policies and plans are targeted to bring the country to be one of the preferred investment destinations in Asia. By the declaration of the National Economic and Social Development plan of 2017-2021, the preparation of the future human resources is aimed at Thai youth and students to bring the country to the new industrial S-curve. Young Thai, especially in tertiary education, is trained oriented towards critical and creative technological atmosphere [1][2]. In addition, critical and creative thinking, a core element of an intellectual complex problem solving, found in a common core as analytical thinking. An ability which an individual is able to analyze and evaluate a choice of solutions to suit a specific problem [3][4]. In accordance to the national policy, Office of Basic Education states learning outcomes of an individual student to be capable of self-directed, highly motivated, and having critical and creative thinking that will contribute to a perpetuate such industry. A step-by-step breaking down a complex problem into a manageable mini component becomes a good practice of an instructional for analytical thinking process. However, the Thai government remarks the issue of the disparity between students from schools in the city and rural caused by a lack of teacher in a specific content of Math and Science in a rural, either an 
experienced teacher with a skill in teaching students' such analytical/higher order thinking skills [5][6][7][8]. To fill the gap of the teaching in this specific content area and the analytical thinking ability, the Ministry of Education invited a research and development of a supplementary classroom with technology for quality of teaching and learning.

Among teaching and learning materials, a paper-based is still an effective learning material despite a widespread an e-book. A textbook allows students to elaborate and extend their thought repeatedly through their touch of fingers, flip, and write for a note taking, incorporated with images, drill and practices, along with sets of exercises which at most accompanied by key answers for those questions in the exercises. With Augmented Reality (AR) technology, a printed material could be augmented with meaningful media for students to play with the contents and their thought, while manipulating the media at their own paces. Manipulative learning materials are typically physical tools of teaching and learning that engage students visually and physically with objects [9]. A use of manipulative learning material helps students construct thinking while discovery during the learning process. Typically, the materials are provided along with a direction, and students explore the materials and ask questions before and during the lesson. With technology augmented to the materials, students could interact with instructional events pre-instructed by teachers. This methodological approach allows a deep learning because students engaged their learning with touchable learning manipulative materials (meaningful single/multiple cards) in a textbook with augmented multimedia activity for mastery skills in analytical thinking. Therefore, this research is aimed to explore the use of single/multiple markers in augmenting media that could help students learning to analyze the concept of Genetics.

\subsection{Research questions}

- What implementation strategy of using some AR markers (single or multiple markers) influences learner performance?

- What implementation strategy of using AR markers (single or multiple markers) influences groups of learners with differing thinking ability skills?

\section{$2 \quad$ Literature Review}

Analytical thinking is an essential ability that enhances a person's diagnostic, evaluation, decision-making, and planning. Analytical thinking performs distinguishing, categorizing elements, its cause and effect which underlying reason. It is actually an analysis of relationship that affects each other by finding what is related, what degree, corresponding or opposing, linking causes and consequences. Analytical or logical thinking is accounted to be a component of critical thinking and problemsolving. Individuals analyze complex problems by finding all possible solutions, then evaluating those solutions and selecting the best one as an answer. It is a process of selecting the best alternative by ordering, comparing, contrasting, evaluating and 
selecting. Analytical thinking is also categorized as part of a "learning transfer" that meaningful learning occurs when students focus on information, its relationships, and apply to other contexts [10][11].

Augmented reality (AR), a technology that simulates 3D, animate, VDO objects for students visually and auditory perceive and virtually interact with objects using computing device with a camera such as mobile phone [12]. Simple display process, an input of a card "marker" processes and locates a preset media to augment on to an object via a real-time video output of a computing device/smartphone.

The affordable AR reality system on desktop and mobile provides opportunities to research the application of the system on educational topics or settings. Examples of the implementation of an AR reality system included an interactive book that applied a traditional book enhanced with AR markers embedded in a particular page or figure. With the use of a smartphone's camera, the markers display 3D animation or additional videos on a specific page. Also, some learning toolkits are designed as cardboard games. The AR application provides virtual renditions of the $3 \mathrm{D}$ animation or meaningful information to the cards that help learners gain a realistic experience while playing, compared to using flat cardboard [13][14].

Technical aspect of AR on learning: Two types of AR application are primary consideration for a learning design: dependent VS independent location. Placedependent $\mathrm{AR}$ is aligned with a specific environment, not applied to other locations. The key point of AR place-dependent is the location where situated learning took place. On the other hands, a place-independent experience is highly portable and has less or no amount of authentic interaction with physical environment [15]. An AR place-independent experience could embed a contextualized learning within a problem-based narrative along with a layer of content for learners to observe, manipulate, and analyze [16].

AR Technology is aligned with constructivist theory and claimed to be a cognitive tool that learners construct new knowledge based on connecting the previous knowledge in a situated learning environment. Besides, the connectionist expands the constructivist that individual constructs knowledge from a connection of memories. Memories are from an encoding process that information converted into memory, and later construct into knowledge. Four primary types of encoding are visual, acoustic, elaborative, and semantic. Visual encoding gives mental pictures and temporarily stored in iconic memory in Amygdala in human brain. Acoustic encoding is the use of auditory stimuli or hearing to implant memories, in a phonological loop. Elaborative encoding uses known information and relates to the new information being experienced. Semantic encoding involves the use of sensory input that has a specific meaning is applied to a context [17][18][19]. The AR technology could set a learning environment for learners to connect with, of which information in a touchable item and augmented displayed in a visual and acoustic format that can be further elaborated.

Related AR technology and research in teaching and learning found several interesting effects. Researchers claim the affordance of AR to students' affective in associated with cognitive learning outcomes, for the sense of presence, immersion, and contextualization. Researchers state that AR is an effective combination of a 
constructivist and visualization learning activities and that $\mathrm{AR}$ in replace to simulation gains learners' involvement, beliefs in augmented media they see, values of a real context encountered with. AR serve as effective resources for immersive contextualization [20][21]. The stronger perception of the learners on the augmented media to be real along with their presences in the environment, resulting a more beneficial to the learning outcomes [21].

AR Technology is strong supported by constructivist theory and claimed to be a cognitive tool that learners construct new knowledge based on connecting the previous knowledge in a situated learning environment. For an example, AR technology has been implemented to build capacity in working, simulated practice allowing anatomical structure prior to surgeries. When perform, observe, or practice a real surgery, medical students can connect their previous knowledge from the virtual practice [16][17].

AR technology, when claimed as a cognitive visualization tool in Chemistry subject [22], demonstrates spatial relationships by overlay a displayed threedimensional object and animation to facilitate students to learn an abstract concept or a subject that require students visual-spatial thinking. Students with visual-spatial ability were reported to spend less cognitive load, but no relation found on less cognitive load and learning performance, either learning in-group. However, research found higher learning performance outcome of students with visual-spatial ability, and also scaffolding technique contribute greatly to the learning achievement.

Besides, the connectionist expands the constructivist that individual constructs knowledge from a connection of memories. Memories are from an encoding process that information converted into memory, and later construct into knowledge. Four primary types of encoding are visual, acoustic, elaborative, and semantic. Visual encoding gives mental pictures and temporarily stored in iconic memory in Amygdala in human brain. Acoustic encoding is the use of auditory stimuli or hearing to implant memories, in a phonological loop. Elaborative encoding uses known information and relates to the new information being experienced. Semantic encoding involves the use of sensory input that has a specific meaning is applied to a context [18]. The AR technology could set a learning environment for learners to connect with, of which information in a touchable item and augmented displayed in a visual and acoustic format that can be further elaborated.

Learners eventually transfer knowledge and procedural rules to other cases. In a mixture of real and virtual objects or actors, participants in an immersive simulation use location-based handheld device to physically walk throughout a real-world location while collecting place-dependent simulated data, interacting with virtual characters, while collaboratively investigating simulated scenario with others [23].

In this study, the focus is on the AR marker with independent-place context; students build knowledge based on analytical thinking when comparing, contrast, and select choices from manipulative and touchable printed markers with augmented media over the choices they make. 


\section{$3 \quad$ Research Methodology}

A quasi-experimental research design was employed in this study. The activity involved a step-by-step scenario or questions on the screen that allows learners to manipulate the AR marker in a cartoon graphic drawing by exposing the marker to the webcam's focus as an input device. Two types of AR markers, single and multiple, were manipulative materials supporting students with high and low analytical thinking to compare and contrast among AR markers with cartoon graphic design and genetic questions/scenarios on the screen. Students expose an AR marker or two AR markers on to the webcam's focus as an input in order to respond to question or scenario on the screen.

The analytical thinking measurement test was developed based on diagnostic, evaluation, and decision-making, to assess students in analyzing complex problems by finding all possible solutions, then evaluating those solutions and selecting the best one as an answer. Researchers gave the test instrument to five experts who are the lecturers in the areas of thinking skills and psychology. These five experts were required to validate the content IOC (Item Objective Congruence) at .82. In addition, the test instrument was given to a group of high school students to rate according to the content validity and its clarity, found clearly understandable. A pilot study was carried out to obtain the reliability with Cronbach's alpha $=0.90$.

AR technology can engage students with an augmented information in a form of graphic or video representing an actual object or place. The Augmented Reality (AR) program used for this research project, relating to Genetics subject for a Thai junior high school. An AR instructional and media design, the AR marker design: single vs multiple markers, Instructional process and Learning system flowchart, and the AR platform are described as following:

\subsection{An instructional AR design}

Augmented Reality (AR), a technology that simulates 3D, animate, VDO objects for students visually and auditory perceive and virtually interact with objects using computing device with camera such as mobile phone. Simple display process, an input of a card "marker" processes and locates a preset media to augment on to an object via a real-time video output of a computing device/smartphone.

Among several types of AR technology, for this media design, based on a manipulative material concept, genetic cartoon image cards are used as a markerbased AR. In this setup, the input hardware recognizes the images on a card; the AR application program recognizes and locates the markers and then projects a mediabased image such as a video on to the card. Students also register a simple 2D cartoon image representing characteristics of persons into their memory. The character of person is obviously shown in the drawing.

An instructional and media design:

- Define learning outcomes

- Create a display information that is relevant to the intended learning outcome 
- Construct a series of items that require students to reasoning their knowledge of the content subject specifically through analyzing and inferring the display information

- Compile with effective test item construction principles

- Design the page layout to display a relationship between the display and each item

- Guiding tasks that are expected students to perform

- Define the criteria to evaluate students' responses

- Review and validate the items [24]

\subsection{The AR marker design: Single vs multiple markers}

Among several types of AR technology, for this media design, based on a manipulative material concept, Genetic cartoon image cards are used as a markerbased AR.

The AR function: The functions designed framework of the AR markers are an answer choice to compare, contrast, and find a rule from a logical circumstance. Instead of answering the question via clicking on the choices appearing on the screen, the proposed program applies AR technology using an AR marker in a printed-paper with a meaningful graphic design as a choice. The markers are designed to be reused across questions on the same topic. Using AR markers as manipulative materials to learn a logical explanation of Genetic. The learners perceive a concrete cartoon images on the AR marker, compare, and categorize the relationship between images on the markers and the augmented information.

Color-coding: The designed AR card as a marker, at each corner of a marker contains a small filled-color square. The AR system used the small square filled with colors on the card as a feature to serve as a marker. The filled colors are yellow, blue, red, and black. The non-ordered combination of these colors produces 36 distinct markers, which provides the maximum number of choices for the learners during the activity.

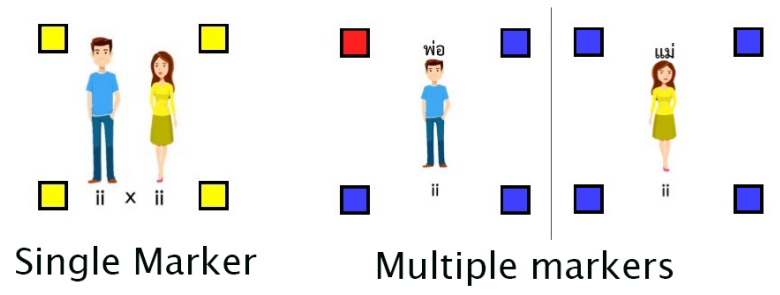

Fig. 1. The AR marker design: single vs multiple markers

A single marker AR design: A single marker allows instructors to post scenarios with certain number of choices that are equal to the number of markers. The design implies problem-based learning narratives presenting students with a scenario, specific information, and a fact pattern. The students' task is to recognize and identify problems that each example represents. Students are required to complete this 
essential step. Problem recognition is a technique for students to develop a valuable diagnostic skill. Five scenarios are presented to students to answer, and with a supported hint. If students fail to answer within a limitation of 12 possible markers (answers) for the first time, and -1 (minus one) for each time of the marker they choose. This means students have 12 times (markers) to answer for the five scenarios.

A multiple-marker design: Using a probability technique on multiple markers, the AR program supports an instructor to post scenarios and increase students' makers to compare, contrast, and choose. With the same five scenarios, students choose two markers at the same time for an answer. This multiple marker provides a possible answer of $12 * 11$ which is 132 possible answers. If the student answers a wrong solution, then the instructor provides a hint in a form of an augmented video or an image overlay the two markers. The instructor can align appropriate hints based on two markers student selected. This design allows an instructor to elicit students' errors and remedial by a hint for students to further their comparison, contrasting, other choices of the markers.

\subsection{Instructional process and learning system flowchart}

Students are step-by-step provided an instruction and problems to be solved, students will respond the one choice of responding is brought to the next questions. Eventually, students will learn from hints and feedbacks that helping them compare and contrast the rest of the choices. The instructional design employs a formative feedback, known as an "assessment for learning", while students learn from the feedback [25][26]. The feedback process is to decide an appropriate direction for students based on evidence received from their responses. One of several formative assessment techniques that selected in this design is "a context-dependent item set" that help instructors in designing scenarios that require students to generate, analyze, compare, and contrast. The item set consists of series of questions that make use of the context. Students use a display information to answer the questions.

The AR system shows and instructs the learner how to use the system and markers in the flowchart. To skip this process, the learner takes the "start" marker to the defined area on the screen. Second, the system shows a question or a command in text, image, or video. Third, the process shows an answer screen containing an answer section. The image captured via webcam overlays the answer section and displays thumbnail images at the top right corner. When students choose a marker in the answer section, the program recognizes the marker and shows a response in an image or a video format in the answer section, as shown in Fig. 2.

When the learner submits the marker to answer the section, the program checks the submitted answer. If the answer is correct, then the program proceeds to the next question. If not, then the program proceeds to show a hint section. For this part of the process, the program may show a hint of an image or a video corresponding to the learner's answer. Once the program provides a hint, then it navigates back to the question and answer process. 


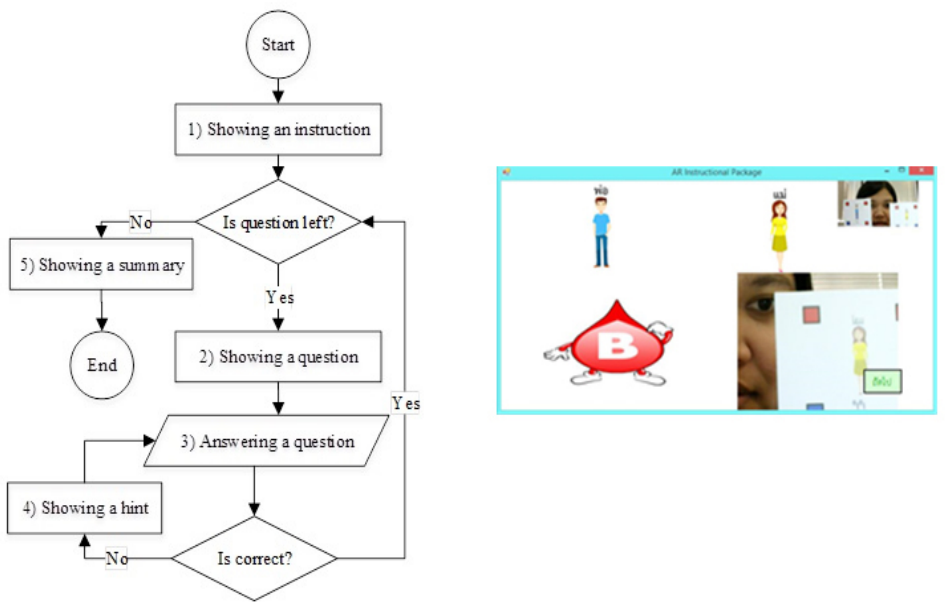

Fig. 2. An instructional process and the AR system

\subsection{System platform}

The program is designed as a window-based application. The $\mathrm{C \#}$ language is used to implement the main graphical user interface and control the process flow. The OpenCvSharp, a wrapper of OpenCV for .NET Framework in C\# language, is used to implement image processing and webcam controlling. The software requirements are Microsoft Window 7 or newer versions, the Microsoft.Net Framework 4.0, and the webcam driver. The minimum hardware requirements are the third generation Intel Core I series, 4 gigabytes system memory, and the HD webcam.

The researchers designed the AR card as a marker. Each corner of a marker contains a small filled-color square. The AR system used the small square filled with colors on the card as a feature to serve as a marker. The filled colors are yellow, blue, red, and black. The non-ordered combination of these colors produces 36 distinct markers, which provides the maximum number of choices for the learners during the assessment.

\subsection{Research procedure}

A paper test on analytical thinking ability was administered to a hundred sampling group. The sampling group was assigned to the low-level analytical thinking skills group based on percentile scores: high-level of analytical thinking ability $\left(100^{\text {th }}-61^{\text {st }}\right.$ percentile) and low-level of analytical thinking ability $\left(33^{\text {rd }}-1^{\text {st }}\right.$ percentile $)$. Each group of high and low thinking ability was thirty students.

Fifteen pairs of students with similar low-level analytical thinking scores were assigned to a group using a single AR marker and the other using multiple AR markers. The same procedure was repeated to the group of high-level analytical thinking skill (see Table 1). 
With four groups identified, all students completed a pretest before the activity. Students were provided a brief instruction about Genetics, specifically a genetic transformation. The AR instruction package was ranged for 100 minutes. Students could repeat the activity as much as they preferred, then the posttest was administered.

Table 1. Distribution of students with different thinking ability skills and the use of AR markers

\begin{tabular}{|l|c|c|c|}
\hline \multicolumn{1}{|c|}{ Analytical thinking } & Single AR Marker & Multiple AR Marker & Total \\
\hline Low-level & Group 1: 15 & Group 3: 15 & 30 \\
\hline High-level & Group 2: 15 & Group 4: 15 & 30 \\
\hline Total & 30 & 30 & 60 \\
\hline
\end{tabular}

\section{$4 \quad$ Findings}

Table 2 shows the results of the comparison between pretest and posttest data collected from the learners in the same category but different groups. The statistics used include mean score (Mean), standard deviation (SD), t-value, and p-value. In addition, Table 3 illustrates the posttest comparison between users of a single AR marker and those using multiple AR markers.

Table 2. Comparison of pretest and posttest results between categories of thinking ability skills and AR marker user groups

\begin{tabular}{|c|c|c|c|c|c|c|c|}
\hline \multirow{2}{*}{\multicolumn{2}{|c|}{ Implementation }} & \multirow{2}{*}{$\begin{array}{c}\text { Thinking } \\
\text { ability skills } \\
\text { category }\end{array}$} & & \multicolumn{4}{|c|}{ Measurement } \\
\hline & & & & Mean & $S D$ & $t$ & $p$ \\
\hline & 1 & Low & Pretest & 4.33 & 0.90 & & \\
\hline & & Low & Posttest & 9.40 & 1.84 & & \\
\hline & 2 & High & Pretest & 9.87 & 1.25 & & \\
\hline & & High & Posttest & 12.80 & 2.08 & & \\
\hline & 3 & Low & Pretest & 4.07 & 0.96 & & \\
\hline & & Low & Posttest & 11.33 & 1.63 & & \\
\hline & 4 & High & Pretest & 10.07 & 1.28 & & \\
\hline & & High & Posttest & 15.40 & 1.50 & & \\
\hline
\end{tabular}

The results from the comparison between pretest and posttest data indicate that the posttest data from all groups significantly reported higher numbers (see Table 3 ). The posttest comparison between user groups (single AR and multiple AR markers) reported significantly higher numbers for those who used multiple AR markers on both low and high-level analytical thinking ability categories (see Table 4). The result seems to imply that using AR for instructional feedback positively influence learners' performance in recall, retention, and analytical thinking. 
Table 3. Comparison of pretest-posttest data from users of single and multiple AR markers across all thinking levels (low vs high)

\begin{tabular}{|c|c|c|c|c|c|c|c|c|}
\hline Implementation & & $\mathbf{N}$ & & SD & df & $\mathbf{t}$ & p & \\
\hline \multirow{2}{*}{$\begin{array}{l}\text { Single AR } \\
\text { Marker }\end{array}$} & Pretest & 30 & 7.10 & 3.01 & \multirow{2}{*}{29} & \multirow{2}{*}{11.148} & \multirow{2}{*}{$.000 *$} & \multirow{2}{*}{$\mathrm{p}<.01$} \\
\hline & Posttest & 30 & 11.10 & 2.59 & & & & \\
\hline \multirow{2}{*}{$\begin{array}{l}\text { Multiple AR } \\
\text { Marker }\end{array}$} & Pretest & 30 & 7.07 & 3.25 & \multirow{2}{*}{29} & \multirow{2}{*}{20.239} & \multirow{2}{*}{$.000 *$} & \\
\hline & Posttest & 30 & 13.37 & 2.58 & & & & \\
\hline
\end{tabular}

Table 4. Comparison of posttest data from users of single AR and multiple AR markers across all thinking categories (low vs high)

\begin{tabular}{|l|l|l|l|l|l|l|l|}
\hline \multicolumn{1}{|c|}{ Implementation } & N & & SD & df & t & \multicolumn{1}{c|}{$\mathbf{p}$} & \\
\hline Single AR Marker & 30 & 11.10 & 2.59 & \multirow{2}{*}{58} & \multirow{2}{*}{3.40} & \multirow{2}{*}{$.001 *$} & $* \mathrm{p}<.0$ \\
\cline { 1 - 8 } Multiple AR Marker & 30 & 13.37 & 2.58 & & & \\
\hline
\end{tabular}

\section{Discussion and Conclusion}

First, the results of the study demonstrated the potential of using Augmented Reality (AR) to support student learning especially in developing analytical thinking ability. Students all group levels of analytical thinking had better learning performance after study from the package. Students had a chance to manipulate learning materials by performing specific cognitive task step-by-step information and hints providing through the instructional system, look through its components, its relationships, and apply to other contexts. Eventually, students could deduct the patterns to be a rule [10]. Independent location type of card marker need not a geographical variable, to display the overlay media on the object and highly portable; in this research embedded contextualized learning within a problem-based narrative along with a layer of content for the learner to observe, manipulate, and analyze. This design in accordance with the previous assumption of Klopfer and Sheldon [14] and Perry et al. [15].

In addition, the meaningful images on the markers associated with the video or image media overlay on to the screen could help reducing cognitive load that improves students' performance. The AR technology provides a learning atmosphere that is curious, motivated, and challenged by fantasy when students interact with information embedded on physical object [19][27]. Psychological learning of constructivist and connectionist could well explain the phenomena of students building a layer of knowledge when interacting with two repetitive media arousements, manipulative cards and augmented media in a virtual format right on to the context of learning. Students construct knowledge from a connection of memories by encoding information on the marker to the memory, then another layer of information is placed in connecting to the previous one.

Second, the finding found that the use of multiple AR markers provides students' performance better than the single card. In this study, students have more choices to compare and logically compare from the probability of 12 markers in double in which the choices of selection become a hundred thirty-two, while the single marker is only twelve choices. The latter one, single could help to scaffold students to go through a 
limited step and come to a conclusion easier. However, the multiple marker gives students more logical choices to compare and contrast than a single one, that could help students gain better score in analytical thinking.

Finally, research should aim to further the study for learners' complex critical and problem-solving in the expansion of this finding; to explore and design with a flexibility of geographical location based Augmented Reality, that could help students to investigate in-depth, connecting possible choices of probability in a situated learning environment, as well as its effect on a contribution of cohort learning.

Although AR still limited to the availability and accessibility in some schools setting, the instructional package with AR markers and downloadable system for offline use could be integrated into the classroom for effective teaching and learning for students' analytical thinking ability

\section{Compliance with Ethical Standards}

Funding: This study was funded for the Innovative Educational Technology Research Unit, Chulalongkorn University in Bangkok, Thailand.

Conflict of Interest: Each author declares that he/she has no conflict of interest.

Ethical approval: All procedures performed in studies involving human participants were in accordance with the ethical standards of the institutional and/or national research committee and with the 1964 Helsinki declaration and its later amendments or comparable ethical standards.

Informed consent: Informed consent was obtained from all individual participants included in the study.

\section{$7 \quad$ References}

[1] NESDB. (2017). The National Economic and Social Development Plan XII, 2017-2021 http://www.nesdb.go.th/ewt_news.php?nid=6420

[2] Mayer, R. E. (1992). Thinking, problem solving, cognition. Second edition. New York: W. H. Freeman and Company.

[3] Bransford, J. D., \& Stein, B. S. (1993). The ideal problem solver: A guide for improving thinking, learning, and creativity (2nd ed.). New York: W.H. Freeman.

[4] Sae-Lao, R. (2013). The logic of the Thai higher education sector on quality assessment policy (Doctoral dissertation, Columbia University).

[5] Soparat, S., Arnold, S.R., \& Klaysom, S. (2015). The development of Thai learners' key competencies by project-based learning using ICT. International Journal of Research in Education and Science (IJRES), 1(1), 11-22. https://doi.org/10.2 1890/ijres.01778

[6] Art-In, S., \& Tang, K. N. (2017). Development of analytical thinking skills among Thai university students. The Turkish Online Journal of Educational Technology.

[7] Changwong, K., Sukkamart, A., \& Sisan, B. (2018). Critical thinking skill development: Analysis of a new learning management model for Thai high schools. Journal of International Studies Vol, 11(2). https://doi.org/10.14254/2071$\underline{8330.2018 / 11-2 / 3}$ 
[8] Morrow, L. M. (1982). Manipulative Learning Materials: Merging Reading Skills with Content Area Objectives. Journal of Reading, 25(5), 448-453.

[9] Saengprom, N., Erawan, W., Damrongpanit, S. and Sakulku, J. (2015). Exploring the different trajectories of analytical thinking ability factors: An application of the secondorder growth curve factor model. Educational Research and Reviews, 10(7), 994-1002 https://doi.org/10.5897/ERR2015.2112

[10] Starcic, A. I., Turk, Ž., \& Zajc, M. (2015). Transforming pedagogical approaches using tangible user interface enabled computer assisted learning. International Journal of Emerging Technologies in Learning (iJET), 10(6), 42-52 https://doi.org/10.3 991/ijet.v10i6.4865

[11] Yuen, S. C. Y., Yaoyuneyong, G., \& Johnson, E. (2011). Augmented reality: An overview and five directions for AR in education. Journal of Educational Technology Development and Exchange (JETDE), 4(1), 11. https://doi.org/10.18785/jetde.0401.10

[12] Ozdamli, F., \& Hursen, C. (2017). An Emerging Technology: Augmented Reality to Promote Learning. International Journal of Emerging Technologies in Learning (iJET), 12(11), 121-137 https://doi.org/10.3991/ijet.v12i11.7354

[13] Cai, S., Wang, X., \& Chiang, F-K. (2014). A case study of Augmented Reality simulation system application in a chemistry course. Computers in Human Behavior, 37(2014), 31-40 https://doi.org/10.1016/j.chb.2014.04.018

[14] Klopfer, E., \& Sheldon, J. (2010). Augmenting your own reality: Student authoring of science-based augmented reality games. New Directions for Youth Development, 128(Winter), 85-94 https://doi.org/10.1002/yd.378

[15] Perry, J., Klopfer, E., Norton, M., Sutch, D., Sandford, R., \& Facer, K. (2008). AR gone wild: Two approaches to using augmented reality learning games in zoos. Proceedings of the 8th International Conference on International Conference for the Learning Sciences, The Netherlands, (pp. 322-329). http://hdl.handle.net/1721.1/100459

[16] Novella, S. (2018). Augmented Reality in Medicine. Science-based medicine. March 28, 2018. Available at https://sciencebasedmedicine.org/augmented-reality-inmedicine/

[17] Murthi, S., \& Varshney, A. (2018). How augmented reality will make surgery safer: Harvard Business review. March 20, 2018. Available at https://hbr.org/2018/03/howaugmented-reality-will-make-surgery-safer

[18] Lumen. 2018. Boundless Psychology. Available at https://courses.lumenlearning.com/boundless-psychology/chapter/step-1-memoryencoding/

[19] Dunleavy, M. (2014). Design principles for augmented reality learning. TechTrends, 58(1), 28-34. https://doi.org/10.1007/s11528-013-0717-2

[20] Toledo-Morales, P., \& Sanchez-Garcia, J. M. (2018). Use of Augmented Reality in Social Sciences as Educational Research. Turkish Online Journal of Distance Education, 19(3), 38-52. https://doi.org/10.17718/tojde.444635

[21] Chen, Y. H., \& Wang, C. H. (2018). Learner presence, perception, and learning achievements in augmented-reality-mediated learning environments. Interactive Learning Environments, 26(5), 695-708. https://doi.org/10.1080/10494820.2017.1399148

[22] Chen, Y. C. (2013). Learning protein structure with peers in an AR-enhanced learning environment (Doctoral dissertation). Available at http://hdl.handle.net/1773/23622

[23] Dunleavy, M., Dede, C., \& Mitchell, R. (2009). Affordances and limitations of immersive participatory augmented reality simulations for teaching and 
Paper-Implementing Multiple AR Markers in Learning Science Content with Junior High School..

learning. Journal of science Education and Technology, 18(1), 7-22. https://doi.org/10.1007/s10956-008-9119-1

[24] Utah Valley University. (n.d.). Test Writing Tutorial. Retrieved June 23, 2016, from https://sites.google.com/site/testwritingtutorial/home

[25] Clarke, P., Owens, T., \& Sutton, R. (2006). Creating Independent Student Learners, School Leaders: A Practical Guide to Assessment for Learning. Portage \& Main Press.

[26] Glasson, T. (2009). Improving student achievement: A practical guide to assessment for learning. Carlton, South Victoria: Curriculum Press.

[27] Zhao, Q. (2018). The Application of Augmented Reality Visual Communication in Network Teaching. International Journal of Emerging Technologies in Learning (07), 57-70. https://doi.org/10.3991/ijet.v13i07.8780

\section{Authors}

Jaitip Nasongkhla, Associate Professor, Director of Innovative Educational Technology (iNET), Chulalongkorn University, Thailand. Her works have been in supporting Technology and learning in a wide range of target group such as Teacher Education, K-12, learning in a workplace, LLL; covering learning media ,web/mobile learning design, Learning Platforms ,Augmented Reality (AR) Technology. Email id: jaitip.n@chula.ac.th

Chanjaradwichai Supadaec is an adjunct lecturer at the Faculty of Education at Chulalongkorn University, between 2017-2018. His research interests lie in the area of learning management systems, and augmented reality.

Thanyaporn Chiasiriphan is a researcher at Innovative Educational Technology (iNET).

Article submitted 2018-11-13. Resubmitted 2018-12-27. Final acceptance 2019-01-07. Final version published as submitted by the authors. 